\title{
RESEARCH OF VIBROACOUSTIC DIAGNOSTICS OF FUEL SYSTEM OF ENGINES OF COMBINE HARVESTERS
}

Ivan Rogovskii, Liudmyla Titova, Andriy Novitskii, Victor Rebenko

National University of Life and Environmental Sciences of Ukraine, Ukraine rogovskii@nubip.edu.ua, ludmylkatitova@gmail.com,novitskiyav@ukr.net, rebenko@nubip.edu.ua

\begin{abstract}
To determine the diagnostic parameters of the fuel system of engines of grain harvesters, technological and structural parameters of the technical condition were considered. The authors investigate the structural schemes of indicator connection of the purpose (performance) of the fuel system of engines and parameters of the technical state of its structural elements. For example, we consider the modal structure diagram, which characterizes the fuel system of grain harvester engines and parameters of the technical state of their structural elements. For example, we consider the modal structure diagram, which describes the fuel system of the engines. At the highest level there are parameters that describe the process of fuel supply and directly determine the characteristics of injection, or the law of fuel supply. On the lower levels there are parameters that characterize the technical state of the most important elements of the fuel equipment. They are used for elemental diagnostics. Experimental studies of vibration characteristics of nozzles of diesel engines have shown that the energy vibration nozzles manifested most actively at the frequency from $5 \mathrm{kHz}$ to $10 \mathrm{kHz}$. Application of Hilbert's conversion to vibration analysis has made it possible to use the ability to control the identity of nozzles and identify defects, such as breakage of nozzles and spray gun hangs. When the injection pressure changes from $27.0 \mathrm{MPa}$ to $8.0 \mathrm{MPa}$, signal duration, which is measured between the front and rear fronts with maximum amplitudes, decreases 2 times. Application of technological cards together with diagnostic means will allow in 1,5 times to cut down the technical equipment due to technical problems at expense of preventing bursts and reducing the fuel consumption by 5-10\%. The range of sensors for diagnostics of diesels, the basic electric circuit of the tool for measuring the angle are developed for fuel supply, the requirements for the computerized system for bench diagnostics of the fuel equipment.
\end{abstract}

Keywords: vibroacoustic, diagnostic, fuel system, combine.

\section{Introduction}

Technical diagnostics of the fuel system of the engine is an important link in the system for controlling the reliability of combine harvesters [1]. Knowledge of the technical state of the fuel system of the combine engine at any time allows it to be used with the highest efficiency, to determine the amount of work during maintenance and repair [2].

To do this, first of all, diagnostic tools and the diagnostic technology are needed, taking into account new combine harvester models [3].

Creation of a database of diagnostic tools should be carried out on the basis of dynamic diagnostic methods [4], which allow to use for diagnostics the parameters of working processes that directly characterize the state of the object; electronic diagnostic tools are developed [5]. This is especially true with simultaneous work in the direction of mutual adaptation of the means and combines to the diagnosis [6]. This requires the appearance of combines equipped with on-board diagnostics based on built-in sensors and electronic equipment [7].

The urgency of the work is to increase the technical readiness of combines, reduce the fuel consumption and engine power losses due to timely diagnostics of the fuel system of the engine and troubleshooting [8].

\section{Materials and methods}

To examine the mechanisms of vibroacoustic processes arising in the nozzle during fuel injection, two main factors were determined: shock effects of the needle of the sprayer during its lifting and landing and hydrodynamic phenomena; the fuel supply process was analyzed in the outlet section of the fuel line near the nozzle [9].

In the analysis it was taken into account that in the process of fuel supply from the pump to the nozzle with the speed of sound passes the primary pressure wave, and the jump-like transition of the section of the injection fuel to the passage sections of the spray holes leads to a hydraulic impact [10]. At the time of fuel injection through spray holes, the fuel flow had a turbulent character [11]. This caused pulsation of both the flow velocity and the pressure that had a fairly wide range of 
amplitudes [12]. In the analysis of processes, we take into account the developments [13]. In general, the results of the analysis revealed the possibility of diagnosing injectors on a diesel engine by vibroacoustic characteristics, obtaining initial data for selection of measuring and recording equipment, and developing a method of experimental research [14].

It should be pointed out that the state of the plunger pairs of the high-pressure fuel pump affects the nozzle processes. The valve in the closed position has greater impact on the signal, however, that impact is still minimal. Firstly, the engine is V-shaped. Secondly, the frequency of the valve closure has a lower oscillation frequency (approximately 6-8 kHz).

Vibroacoustic diagnostics showed that the neighboring injectors do not affect the nozzle operation signal because of the wave velocity. The injectors do not actuate simultaneously. In addition, the speed of ultrasound propagation in steel is about $5.8 \mathrm{~km} \cdot \mathrm{s}^{-1}$. Taking into account the construction and placement of the injectors on the engine and the time among pulses of neighboring injectors, the signal will go this distance for about 100 times.

The experimental installation for the research in vibration characteristics of diesel nozzles was created on the basis of a computerized measuring device. Signal processing programs, a nozzle testing device and a bench for adjusting the fuel equipment with a stand fuel pump and a set of fuel lines. The vibration accelerator sensor was mounted on the nozzle with a special clamping device.

The experimental installation ensured creation of the required high-speed mode and measurement of fuel supply with an injector. The program of signal processing is carried out on the computer record of the signal from the accelerator sensor and its processing in the mode of spectral analysis of oscillations [15].

At the first stage of the experimental research, an injector with an accelerometer was installed on a bench for adjusting the fuel equipment. The signal from the sensor was fed to the input/output board of the L-1250 signals. Signal registration was carried out at band-filtering with a $9 \mathrm{kHz}$ bandwidth filter, focusing on the range of vibration of the jet from 7 to $16 \mathrm{kHz}$. The signal was recorded to the computer memory buffer.

With the help of spectral analysis of vibration of the nozzle, the range of frequencies was specified, in which the energy of vibrations is most actively displayed. In the course of the research, the speed of the camshaft of the fuel pump varied from idle speed to nominal, and the injection pressure was in the range of 13 to $25 \mathrm{MPa}$. In the processing of the input signal, the influence of the nozzle defects on the amplitude and the phase parameters of the signal, as well as on the vibration spectrum of the nozzle, was analyzed.

At the second stage, research was conducted on the engine of the "Slavutich" combine harvester using a vibration accelerator sensor and a computerized system. The processing of signals was carried out in accordance with the method used for bench testing. The signal recording was carried out at the nominal value of the injection pressure and in simulation of such defects as breakage of the spring and freezing of the spray needle in idle mode. Particular attention was paid to filtering the signal to provide diagnostic information. For the analysis of vibration signals, the transformation (transformation) of Hilbert was used and an option was chosen that allowed the localization of the component of the spectrum containing the diagnostic information.

The nozzle is one of the main elements of the fuel equipment, which affects the formation of the injection characteristics, and especially its final phase. Therefore, estimating the efficiency of nozzles directly on the diesel engine will allow to timely prevent violation of the fuel supply process. One of the possible directions of searching for diagnostic methods is the use of vibroacoustic processes that occur in the nozzle when fuel is injected. The main factors that cause such processes are the impact of the needle spray, when it is raised and lowered, and hydrodynamic phenomena in the process of fuel supply. Consider the mechanism of occurrence of these vibroacoustic processes.

After the pressure wave generated at the pump runs through the fuel line, the pressure in the cavity of the sprayer rises. As soon as this pressure begins to exceed the pressure of the beginning of the needle lift, it separates from the saddle. From that moment on the pressure acts on that part of the needle, which until the lifting of the needle was closed saddle. This leads to a sharp increase in the speed of the needle lift from 1.6 to $2.2 \mathrm{~m} / \mathrm{s}$. Moving the needle with such a speed and the shock nature of its lifting and landing cause intense coincidence and vibration of the nozzle body. 
Using the method of hydrodynamic calculation of the fuel supply process and considering the equation of the boundary conditions for the initial cross section of the fuel line (near the nozzle), you can write the equation of motion of the needle spray in this form:

$$
m_{g} \frac{d^{2} h_{g}}{d t^{2}}=\left(f_{g}-f_{g}^{\prime}\right)\left(P_{f}-P_{f o}\right)-\delta_{p r}\left(h_{g}-h_{p r}\right)+f_{g}^{\prime} P_{f}^{\prime},
$$

where $\delta_{p r}-$ stiffness of the spring, $\mathrm{N} \cdot \mathrm{m}^{-1}$;

$m_{g}$ - needle weight, $\mathrm{kg}$;

$h_{g}$ - needle lift, m;

$h_{p r}$ - preliminary compression of the spring, $\mathrm{m}$;

$f_{g}$ - cross-sectional area of the needle, $\mathrm{mm}^{2}$;

$f_{g}$ - area determined by the seat diameter of the needle cone, $\mathrm{mm}^{2}$;

$P_{f}, P_{f_{o}}$ - fuel pressure in the cavity of the sprayer above the stop cone current and at the moment when the needle is started, MPa;

$P_{f}^{\prime}$ - pressure between the shutter cone and spray nozzles (counter pressure), MPa; $t$ - time, s.

From the above equation (1) it can be seen $m_{g} \frac{d^{2} h_{g}}{d t^{2}}$ that the value that determines the intensity of the needle's impact upon reaching the stop will depend on the effort of the previous tightening of the nozzle spring $P_{z}=\delta_{p r} h_{p r}$.

Thus, the oscillatory processes in the nozzle, which are caused by the shock effects of the needle, are due to the tightening force of the spring of the nozzle. Therefore, the change in $P_{z}$ during the operation will directly affect the parameters of the vibration signal.

Analysis of works in this direction [7;14] shows that the energy of vibration of nozzles most actively manifests itself in the frequency range from 12 to $18 \mathrm{kHz}$. The frequency of intrinsic vibration of the nozzle is in the ultrasonic frequency range. However, the authors are ambiguous in the impact of the needle spray on the vibration characteristics of the nozzle. The most practical, from a practical point of view, is the use of the vibration characteristics of the nozzles to assess the identity of their operation on the diesel engine, to determine the angle of advance of the start of the injection, to detect failures, such as breakage of the nozzle spring and freezing of the spray needle.

The research was conducted to use vibration characteristics to assess the technical condition of nozzles. For this purpose an experimental installation was prepared (Fig. 1).
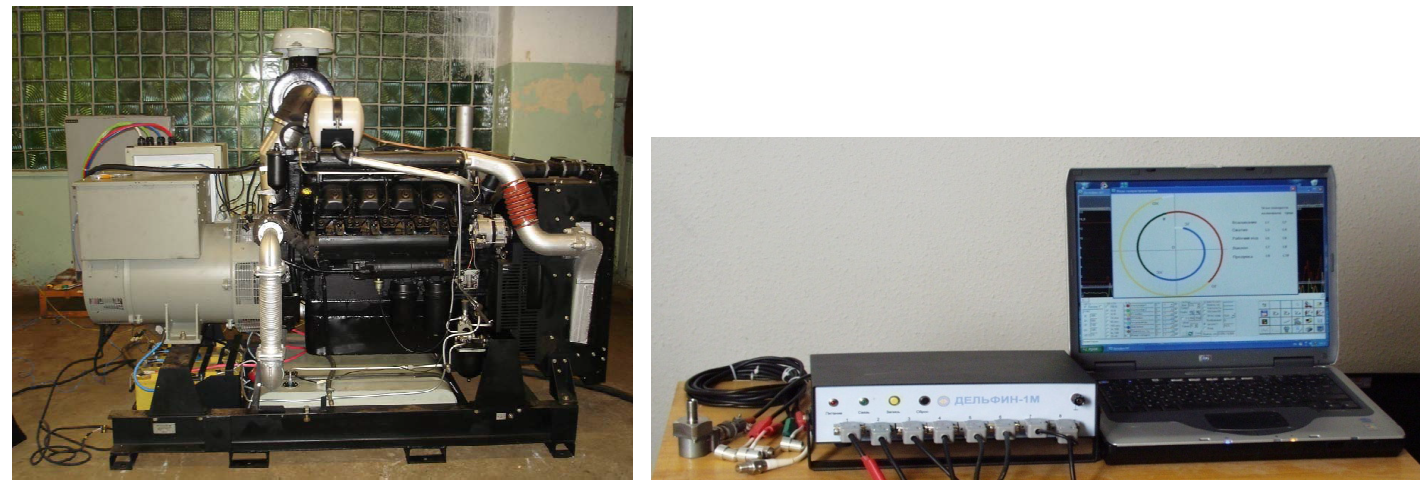

Fig. 1. Experimental installation and stand of vibroacoustic diagnostics

The study used a standard diagnostic kit for diesel engines, namely: two ultrasound transducers and a low-pass sensor mounted on the engine head; a sensor of a "diesel" binder and a high frequency sensor mounted on each high pressure fuel line and nozzle, respectively. The aim was to determine the dynamic performance indicators of the fuel pump plunger and the operation of the nozzle of the selected section. Experiments were conducted for each engine cylinder separately, which made it possible then to compare the results between them.

The general picture of the performance indicators of the first section of the fuel pump and the first engine cylinder jet is shown in Fig. 2. 


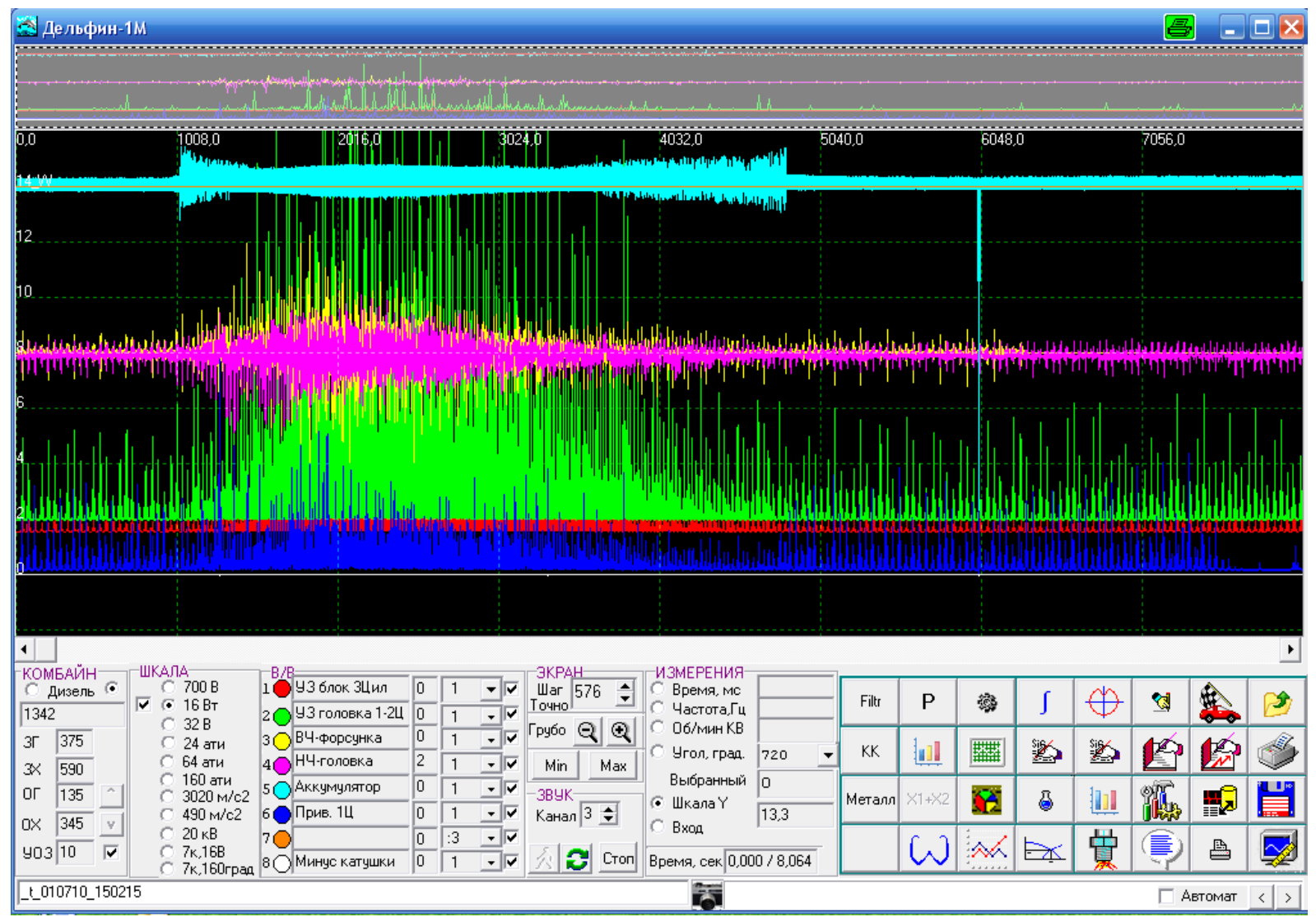

Fig. 2. Indicators of operation of first section of fuel pump and first cylinder engine jet

For a more detailed analysis of the results, we have identified and left on the screen only those sensor values that are needed for the study, which can be seen in Fig. 3.

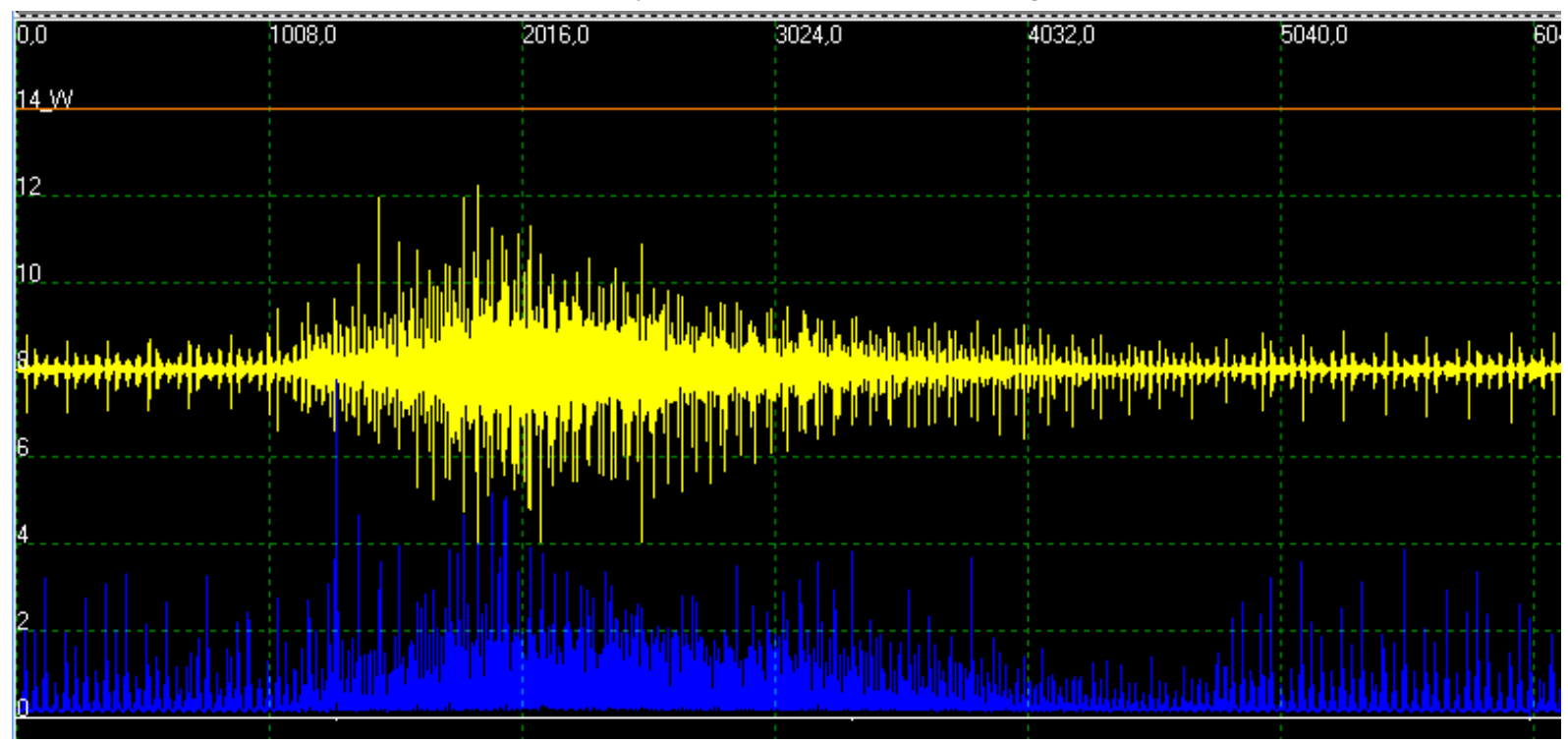

Fig. 3. Indicators of sensors for binding diesel (bottom) and high frequency sensor (on top)

According to the results of the taken indices, the tensile time of the fuel spray nozzle, which was on average 1.5...2 ms. depending on the operating mode of the diesel engine, was estimated. The time of transfer of pressure from the plunger to the nozzle is $0.47 \mathrm{~ms}$.

Having removed the figures from the fuel system of the diesel engine, the following conclusions came. The shut-off valves of the fuel pump plunger are not in the best condition, this is said to be uneven sensor displays. This indicates that the valves already have certain deposits. It is also possible to say with certainty that the valve status is closely linked to the quality of modern diesel fuel. The 
spray nozzles have a marked cramming of seats, which is reflected on the oscillogram in smoother features of the opening and closing of injectors, when the new features are as sharp as possible.

More thorough research was carried out on the diagnostic parameters of the engine nozzles. Analyzing the operation of the nozzle according to the high frequency sensor, it is evident that when the nozzle opens, it behaves rather quietly, moving components (needle) do not have shock contacts with other parts of the design. Such work is provided primarily by countering the nozzle spring and centering the spray needle with the pressure of the injected fuel. After the characteristic fuel injection into the combustion chamber, the injector closes, which is characterized by a powerful splash of the high-frequency components of the indicators. This is due to the very essence of the injection at the moment. The nozzle should maximally sharply complete the injection process, depending on the flow of fuel in the sprayer. If the nozzle does not close quickly enough, the fuel remains in the spray gun, which in the future will affect the coke of the spray, which leads to violation of the spark ignition and burning of fuel. As a result, the toxicity of the exhaust gases of the engine increases. These all factors entail a loss of powerful characteristics and increased fuel consumption by the engine, which in the future will necessarily affect the cheap repair of fuel equipment.

Having examined the work of the nozzles of the second cylinder, a defect was found, namely: coking the seat of the needle sprayer. This is evident from the oscillogram depicted in Fig. 4: the absence of sharp bursts of closure of the nozzle marks the difficult movement of the spray needle and the unclear completion of the process of fuel injection into the combustion chamber.

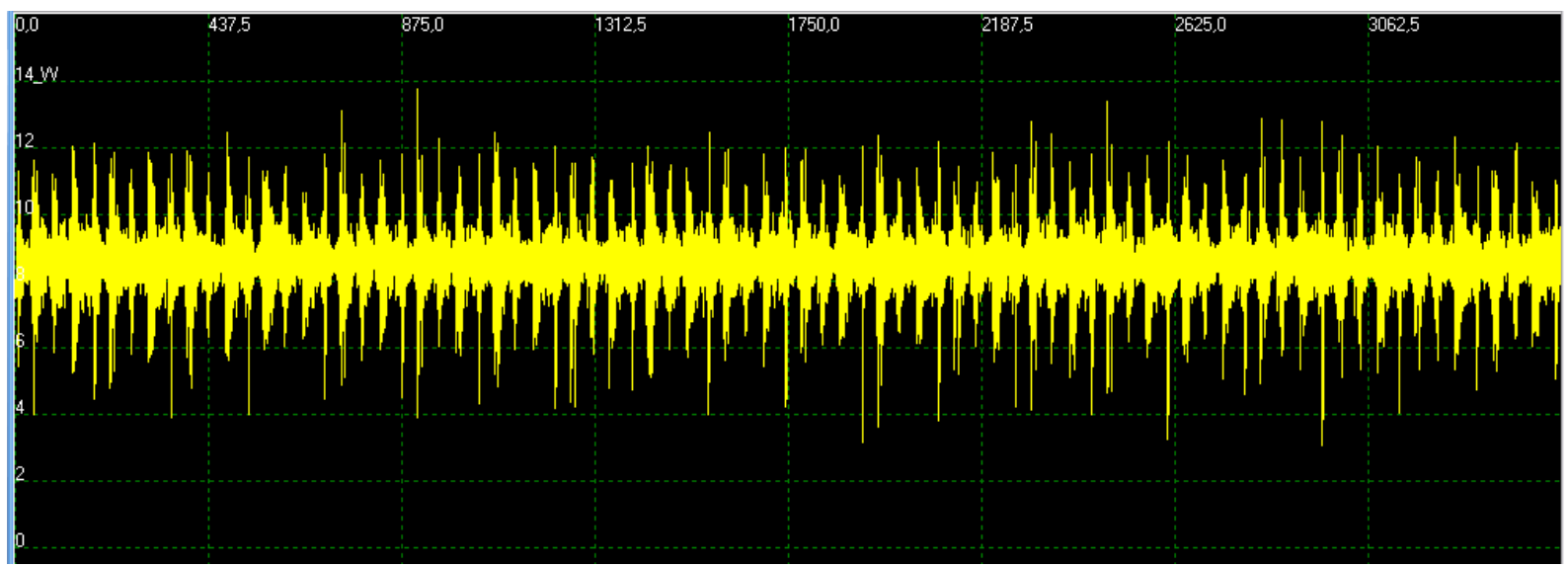

Fig. 4. Work of second cylinder nozzle

Characteristics of the third cylinder nozzle are shown in Fig. 5. The nozzle has somewhat overestimated closing energy by the high frequency signal of the sensor, indicating that the needle is pinched and its seat is activated.

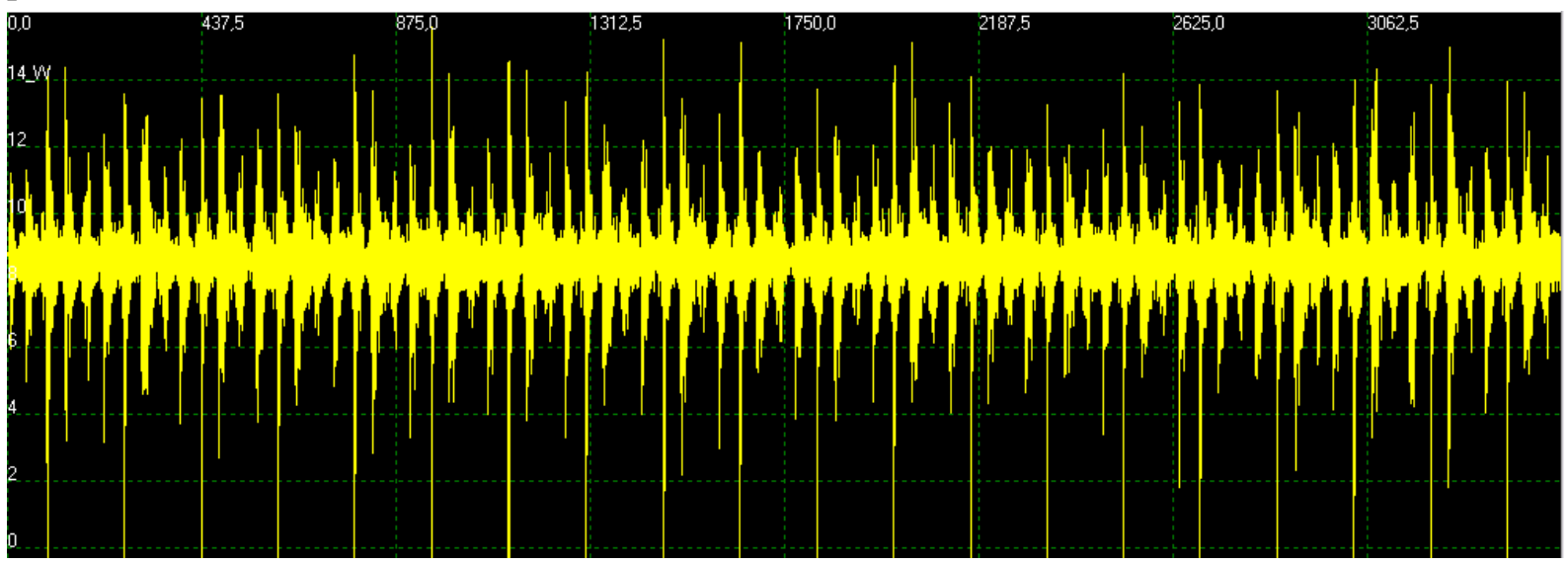

Fig. 5. Work of third cylinder jet

On the sensor signal, as in the Hilbert transform, there are clearly two characteristic vibro-pulses that correspond to the lifting and planting of the spray needle. With an increase in the frequency of rotation in 2 times, the amplitude of the first vibration impulse increases. At the next stage, the failure of the spring of the nozzle was imitated by a decrease in the pressure $\mathrm{P}_{f}$ from $27.0 \mathrm{MPa}$ to to $8.0 \mathrm{MPa}$. 
The position of the rail of the pump remained unchanged. In the mode $\mathrm{n}=300 \mathrm{~min}^{-1}$, the amplitude of the second vibrational pulse decreased by 1.5 times. With an increase in the frequency of rotation at such a defect, the amplitude of the first vibration impulse increases by 6 times, and the second vibrational pulse disappears, even visually reflecting such a malfunction of the nozzle.

One of the implementations of vibration of the nozzle during the hole of a spray needle. The tightness of the sprayer is unsatisfactory; the cyclic feed has decreased to $8.7 \mathrm{~mm}^{3} /$ cycle. Such a defect results in significant changes in the signal of the vibration sensor. Its duration increases 3 times, and the amplitude decreases by 4 times. These changes also reflect the Hilbert's conversion. The decrease in the amplitude of the vibration signal is due to the fact that, when the needle is in a stale state, the fuel enters the spray holes without delay. As a result, the pressure decreases before the spray holes, which reduces the velocity of the turbulent motion of the particles of fuel, which also determines the energy of vibration of the nozzle. A similar phenomenon is observed in the case of weakening of the tightening of the spring due to its breakdown. Fuel, practically, freely passes through the sprayer. With an increase in the speed of a sharp increase in the fuel pressure, the intensity of vibrations increases.

\section{Results and discussion}

In general, the results of the conducted experiments indicate the possibility of assessing the identity of the nozzles and detecting such defects as breakage of the spring and freezing of the needle spray vibration acoustic parameters.

On the basis of consideration and analysis of the existing diagnostic technologies, a list of diagnostic parameters of the technical condition of the diesel fuel equipment is given in Table.

\section{Diagnostic parameters of the technical state of the fuel system}

\begin{tabular}{|c|c|}
\hline $\begin{array}{c}\text { Fuel system and its } \\
\text { components }\end{array}$ & Parameter name \\
\hline Fuel pump & $\begin{array}{c}\text { Setting angle of the beginning of injection (supply) of fuel. } \\
\text { The starting angle for fuel injection }\end{array}$ \\
\hline $\begin{array}{c}\text { Revolutionary regulator } \\
\text { Automatic fuel outflow } \\
\text { coupling }\end{array}$ & $\begin{array}{c}\text { Frequency of rotation of the crankshaft (minimum, maximum). } \\
\text { Uneven frequency of rotation of the crankshaft } \\
\text { Change the starting angle of the fuel supply }\end{array}$ \\
\hline Plunger pair & Pressure that develops a plunger pair at the starting speed \\
\hline Pressure valve & Tightness \\
\hline Nozzle & Injection pressure \\
\hline $\begin{array}{c}\text { Fuel suction pump } \\
\text { Pressure before the filter of fine fuel cleaning during crankshaft } \\
\text { scrolling of the launcher and off fuel feed. }\end{array}$ \\
\hline $\begin{array}{c}\text { Filter for fine fuel } \\
\text { cleaning }\end{array}$ & $\begin{array}{c}\text { Pressure at the inlet to the filter when the fuel is fed manually by a } \\
\text { suction pump and an open outlet from the filter }\end{array}$ \\
\hline
\end{tabular}

The sequence of diagnostics of the fuel system of combine engines depends on specific production conditions, accepted organizational forms of maintenance, availability of diagnostic tools and other factors. In general, the diagnostic process is constructed in such a way as to avoid performing unnecessary work and unnecessarily loading the process with simple prophylactic operations. The basic principle is that a deep check of the state of the components of the machine must be performed only in the case of a real need. Otherwise, they are limited to a general check of the quality of functioning of the components and the state of adjustment of parameters.

The computerized diagnostic system of the combustion engine fuel system includes the following requirements:

1. analog input and $\mathrm{I} / \mathrm{O}$ of digital information via a L-1250 type card;

2. bit $12(16)$ bit; 
3. number of input channels -16 ;

4. range of input voltages - from $0.1 \mathrm{~V}$ to $10 \mathrm{~V}$;

5. presence of sensors for receiving pressure signals in the fuel supply system, the provisions of the top dead point of the camshaft pump, vibration sensors for information on the phase parameters of the fuel supply;

6. recording and displaying on the monitor the characteristics of the pressure change in the fuel line;

7. presence of amplifiers, signal switches, the ability to synchronize signals;

8. signal processing program should provide digital filtering, signal integration, spectral analysis of signals from vibration detectors based on the Hilbert's quick conversion.

The composition and number of sensors are determined by a set of diagnostic parameters that are measurable, taking into account a number of technical requirements.

Electronic resources, in our opinion, should be used, first of all, to measure the diagnostic parameters that characterize working of the diesel system.

The diagnostic parameters that reflect the working processes, such as the characteristic of pressure change in the fuel line of high pressure, contain several diagnostic features. Thus, the residual pressure in the fuel line characterizes the state of the pressure valve and the needle of the sprayer; the velocity of pressure increase in the fuel line depends on the state of the plunger pairs. The maximum pressure determines the tightening pressure of the nozzle spring.

At the same time, the characteristic of the pressure change in the fuel line contains signs of too different levels. So, the residual pressure and the maximum pressure in the fuel line can differ in 5-10 times, which imposes rigid requirements on the sensors for accuracy and overload capability.

Frequency range of the change of the diagnostic parameters of vibroacoustic processes in diesel jet nozzles is $10-20 \mathrm{kHz}$, parameters of working processes of $5-10 \mathrm{kHz}$. The oil pressure in the lubrication system has a pulsating pattern relative to the average level with a pulsation frequency of up to $40 \%$.

The sensors must have a sufficiently high output signal, linearity of the output characteristics throughout the operating range, (1.5-2.0) - double load capacities and the stability of the output characteristics.

In addition, the sensors demand interchangeability. This is especially necessary in the analysis of the identity of processes, such as the characteristics of the pressure change in the fuel line along the lines of injection.

\section{Conclusions}

1. Investigation of the vibration characteristics of the nozzles of diesel engines showed that the energy of vibration of the nozzle is most actively manifested at a frequency from $5 \mathrm{kHz}$ to $10 \mathrm{kHz}$.

2. The use of the Hilbert's conversion to analyze the vibration signal enabled it to be used to control the identity of the nozzles and to identify defects, such as breakage of the nozzle spring and freezing of the spray needle. When the injection pressure is changed from 27.0 MPa to 8.0 MPa, the signal duration, which is measured between the front and rear fronts with maximum amplitudes, is reduced by a factor of 2 .

\section{Acknowledgements}

This work was supported by a grant of the Ministry of Science and Education of Ukraine, contract _110/495/01.01.2016, Project code: UA 1649501 01, NULES Project title - "Experimental researches of parameters and modes of functioning of system of maintenance of agricultural machinery", phase 2: Experimental researches of parameters and modes of functioning of system of maintenance of harvesting combine.

\section{References}

[1] Sergejeva N., Aboltins A., Strupule L., Aboltina B. Mathematical knowledge in elementary school and for future engineers. Proceedings of 17th International Scientific Conference 
"Engineering for rural development". Jelgava, Latvia, May 23-25, 2018, Latvia University of Agriculture. Faculty of Engineering. Vol. 17, pp. 1166-1172.

[2] Bulgakov V., Nikolaenko S., Holovach I., Ivanovs S., Vartukapteinis K. Theoretical investigations of oscillations of root crop head cleaner hanged on integral row-crop tractor. Proceedings of 16th International Scientific Conference "Engineering for rural development". Jelgava, Latvia, May 24-26, 2017, Latvia University of Agriculture. Faculty of Engineering. Vol. 16, pp. 1395-1408.

[3] Dubbini M., Pezzuolo A., De Giglio M., Gattelli M., Curzio L., Covi D., Yezekyan T., Marinello F. Last generation instrument for agriculture multispectral data collection. CIGR Journal, vol. 19, 2017, pp. 158-163.

[4] Yata V.K., Tiwari B.C., Ahmad, I. Nanoscience in food and agriculture: research, industries and patents. Environmental Chemistry Letters, vol. 16, 2018, pp. 79-84.

[5] Masek J., Novak P., Jasinskas A. Evaluation of combine harvester operation costs in different working conditions. Proceedings of 16th International Scientific Conference "Engineering for rural development". Jelgava, Latvia, May 24-26, 2017, Latvia University of Agriculture. Faculty of Engineering. Vol. 16, pp. 1180-1185.

[6] Ivanovs S., Bulgakov V., Nadykto V., Kuvachov V. Theoretical investigation of turning ability of two-machine sowing aggregate. Proceedings of 17th International Scientific Conference "Engineering for rural development". Jelgava, Latvia, May 23-25, 2018, Latvia University of Agriculture. Faculty of Engineering. Vol. 17, pp. 314-322.

[7] Rogovskii I., Grubrin O. Accuracy of converting videoendoscopy combine harvester using generalized mathematical model. Scientific Herald of National University of Life and Environmental Science of Ukraine. Series: technique and energy of APK. Kyiv, Ukraine. vol. 298, 2018, pp. 149-156. doi: 10.31548/me.2018.04.149-156.

[8] Viba J., Lavendelis E. Algorithm of synthesis of strongly non-linear mechanical systems. In Industrial Engineering - Innovation as Competitive Edge for SME, 22 April 2006. Tallinn, Estonia, pp. 95-98.

[9] Luo A.C.J., Guo Y. Vibro-impact Dynamics. Berlin: Springer-Verlag, 2013. 213 p.

[10] Gorobets V.G., Trokhaniak V.I., Rogoskii I.L., Titova L.L., Lendiel T.I., Dudnyk A.O., Masiuk M.Yu. The numerical simulation of hydrodynamics and mass transfer processes for ventilating system effective location. INMATEH. Agricultural Engineering. Bucharest. Romania, vol. 56, No 3, 2018, pp. 185-192. Scopus. WoS.

[11] Astashev V., Krupenin V. Efficiency of vibration machines. Proceedings of 16th International Scientific Conference "Engineering for rural development". Jelgava, Latvia, May 24-26, 2017, Latvia University of Agriculture. Faculty of Engineering. Vol. 16, pp. 108-113.

[12]Zagurskiy O., Ohiienko M., Rogach S., Pokusa T., Titova L., Rogovskii I. Global supply chain in context of new model of economic growth. Conceptual bases and trends for development of social-economic processes. Monograph. Opole. Poland, 2018, pp. 64-74.

[13] Drga R., Janacova D., Charvatova H. Simulation of the PIR detector active function. Proceedings of 20th International conference on Circuits, Systems, Communications and Computers (CSCC 2016), July 14-17, 2016, E D P Sciences, 17 Ave Du Hoggar Parc D Activites Coutaboeuf Bp 112, F-91944 Cedex A, France, vol. 76, UNSP 04036.

[14] Novotny J. Technical and natural sciences teaching at engineering faculty of FPTM UJEP. Proceedings of 15th International Scientific Conference "Engineering for rural development". Jelgava, Latvia, May 23-25, 2016, Latvia University of Agriculture. Faculty of Engineering. Vol. 15, pp. 16-20.

[15] Pinzi S., Cubero-Atienza A.J., Dorado M.P. Vibro-acoustic analysis procedures for the evaluation of the sound insulation characteristics of agricultural machinery. Journal of Sound and Vibration, vol. 266 (3), 2016, pp. 407-441. 